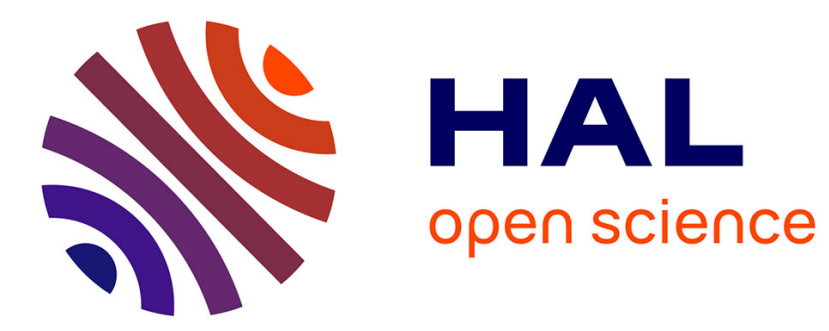

\title{
Micro-supercapacitors from carbide derived carbon (CDC) films on silicon chips
}

Peihua Huang, Min Heon, David Pech, Magali Brunet, Pierre-Louis Taberna, Yury Gogotsi, Samuel Lofland, Jeffrey D. Hettinger, Patrice Simon

\section{- To cite this version:}

Peihua Huang, Min Heon, David Pech, Magali Brunet, Pierre-Louis Taberna, et al.. Microsupercapacitors from carbide derived carbon (CDC) films on silicon chips. Journal of Power Sources, 2013, vol. 225, pp. 240-244. 10.1016/j.jpowsour.2012.10.020 . hal-01159879

\author{
HAL Id: hal-01159879 \\ https://hal.science/hal-01159879
}

Submitted on 4 Jun 2015

HAL is a multi-disciplinary open access archive for the deposit and dissemination of scientific research documents, whether they are published or not. The documents may come from teaching and research institutions in France or abroad, or from public or private research centers.
L'archive ouverte pluridisciplinaire HAL, est destinée au dépôt et à la diffusion de documents scientifiques de niveau recherche, publiés ou non, émanant des établissements d'enseignement et de recherche français ou étrangers, des laboratoires publics ou privés. 


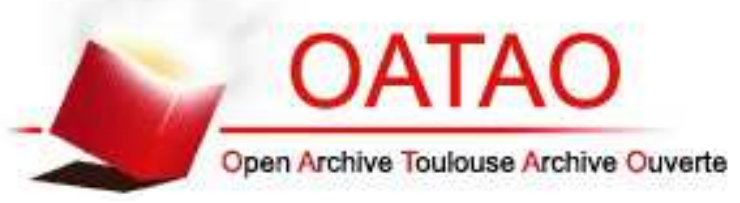

\section{Open Archive TOULOUSE Archive Ouverte (OATAO)}

OATAO is an open access repository that collects the work of Toulouse researchers and makes it freely available over the web where possible.

This is an author-deposited version published in : http://oatao.univ-toulouse.fr/ Eprints ID : 13898

To link to this article : DOI:10.1016/j.jpowsour.2012.10.020

URL : http://dx.doi.org/10.1016/j.jpowsour.2012.10.020

\section{To cite this version :}

Huang, Peihua and Heon, Min and Pech, David and Brunet, Magali and Taberna, Pierre-Louis and Gogotsi, Yury and Lofland, Samuel and Hettinger, Jeffrey D. and Simon, Patrice Micro-supercapacitors from carbide derived carbon (CDC) films on silicon chips. (2013) Journal of Power Sources, vol. 225. pp. 240-244. ISSN 0378-7753

Any correspondance concerning this service should be sent to the repository administrator: staff-oatao@ listes-diff.inp-toulouse.fr 


\title{
Short communication
}

\section{Micro-supercapacitors from carbide derived carbon (CDC) films on silicon chips}

\author{
Peihua Huang ${ }^{\mathrm{a}, \mathrm{b}, \mathrm{c}}$, Min Heon ${ }^{\mathrm{e}}$, David Pech ${ }^{\mathrm{a}, \mathrm{b}}$, Magali Brunet ${ }^{\mathrm{a}, \mathrm{b}, *}$, Pierre-Louis Taberna ${ }^{\mathrm{c}, \mathrm{d}}$, Yury Gogotsi ${ }^{\mathrm{e}}$, \\ Samuel Lofland ${ }^{\mathrm{f}}$, Jeffrey D. Hettinger ${ }^{\mathrm{f}}$, Patrice Simon ${ }^{\mathrm{c}, \mathrm{d}}$
}

\author{
${ }^{a}$ CNRS, LAAS, 7 avenue du colonel Roche, F-31400 Toulouse, France \\ ${ }^{\mathrm{b}}$ Univ de Toulouse, LAAS, F-31400 Toulouse, France \\ ${ }^{c}$ Univ Paul Sabatier, CIRIMAT UMR-CNRS 5085, F-31062 Toulouse Cedex 4, France \\ ${ }^{\mathrm{d}}$ Réseau sur le Stockage Electrochimique de l'Energie (RS2E), FR CNRS, Toulouse, France \\ e Department of Materials Science Engineering and A.J. Drexel Nanotechnology Institute, Drexel University, Philadelphia, PA 19104, USA \\ ${ }^{\mathrm{f}}$ Department of Physics and Astronomy, Rowan University, Glassboro, NJ 08028, USA
}

On-chip micro-supercapacitors were fabricated based on TiC-CDC films.

$\mathrm{TiC}-\mathrm{CDC}$ films are pure carbon films without organic binders.

Micro-supercapacitors were produced based on standard microfabrication steps.

Ideal capacitive behavior is demonstrated with two types of current collectors.

Low series resistance was achieved.

Keywords:

Carbide derived carbon

Micro-supercapacitors

MEMS

Electrochemical capacitor

\begin{abstract}
A B S T R A C T
Interdigitated on-chip micro-supercapacitors based on Carbide Derived Carbon (CDC) films were fabricated and tested. A titanium carbide (TiC) film was patterned and treated with chlorine to obtain a $\mathrm{TiC}$ derived carbon ( $\mathrm{TiC}-\mathrm{CDC}$ ) film, followed by the deposition of two types of current collectors (Ti/Au and $\mathrm{Al}$ ) using standard micro-fabrication processes. CDC based micro-supercapacitors were electrochemically characterized by cyclic voltammetry and impedance spectroscopy using a $1 \mathrm{M}$ tetraethylammonium tetrafluoroborate, $\mathrm{NEt}_{4} \mathrm{BF}_{4}$, in propylene carbonate (PC) electrolyte. A capacitance of $0.78 \mathrm{mF}$ for the device and $1.5 \mathrm{mF} \mathrm{cm}^{-2}$ as the specific capacitance for the footprint of the device was measured for a $2 \mathrm{~V}$ potential range at $100 \mathrm{mV} \mathrm{s}^{-1}$. A specific energy of $3.0 \mathrm{~mJ} \mathrm{~cm}{ }^{-2}$ and a specific power of $84 \mathrm{~mW} \mathrm{~cm}^{-2}$ were calculated for the devices. These devices provide a pathway for fabricating pure carbon-based microsupercapacitors by micro-fabrication, and can be used for powering micro-electromechanical systems (MEMS) and electronic devices.
\end{abstract}

\section{Introduction}

The development of Micro-Electro-Mechanical Systems (MEMS) allows new functions to portable electronic devices without compromising their size. Therefore, decreasing the size of power sources becomes a key objective for fitting the operating envelope of the small devices. Li-ion micro-batteries are the most widely used power sources nowadays. While extensive research has significantly enhanced performance levels since early 1990s [1,2], redox reaction rates limit their power performance. Although this

\footnotetext{
* Corresponding author. CNRS, LAAS, 7 avenue du colonel Roche, F-31400 Toulouse, France. Tel.: +33 561336221; fax: +33 561336208 .

E-mail address: mbrunet@laas.fr (M. Brunet).
}

shortcoming has been tackled by using new designs, such as 3-dimensional [3] and thin-film electrodes [4], there is a demand for higher power devices.

Electrical double-layer capacitors (EDLC or supercapacitors), which store energy by adsorption and desorption of ions from the electrolyte driven by an applied potential at the surface of porous active materials, are able to deliver energy in short time, thus offering high power capability. Implementation of electrochemical micro-supercapacitors on a chip has therefore attracted significant interest as a potential replacement or complementing device for micro-batteries in order to enhance the total performance of the power source.

EDLCs operate within a voltage window up to $3 \mathrm{~V}$ by using an organic electrolyte to achieve high energy and power performance [5]. However, as it is difficult to process carbon powders into films 


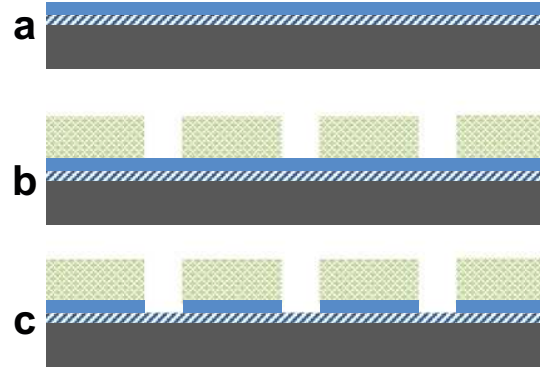

d

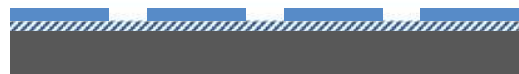

e

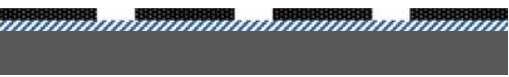

f

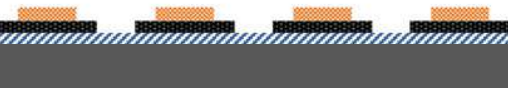

- $\mathrm{TiC}$

$\mathrm{SiO}_{2}$

$\mathrm{Si}$

inic-CDC

Current

Collector

Photoresist

Fig. 1. Schematic illustration of the fabrication process for micro-supercapacitors: a) As-received $\mathrm{Si} / \mathrm{SiO}_{2} / \mathrm{TiC}$ wafer; b) Photolithography; c) Reactive ion etching (RIE); d) Removal of photoresist by acetone and chromosulfuric acid; e) Chlorination; f) Current collector deposition.

using conventional micro-fabrication processes, the development of micro-supercapacitors still poses a challenge. Although demonstrating the proof-of-concept, first trials of carbon-based microsupercapacitors [6,7] showed modest performance (specific capacitance of $0.8 \mathrm{mF} \mathrm{cm}^{-2}$, voltage window limited to $0.8-1 \mathrm{~V}$ ). Subsequent experiments reported on the use of thicker electrodes (up to $50 \mu \mathrm{m}$ ) prepared by the addition of a binder [8] and novel approaches that implemented vertically-aligned carbon nanotubes (CNTs) [9], leading to the improved performance with specific capacitance reaching $90 \mathrm{mF} \mathrm{cm}{ }^{-2}$ [8]. However, powder electrodes need the addition of a binder and nanotube electrodes have a low volumetric energy density, which limits their performance. There is the need for a binder-free carbon thin-film with an adapted microfabrication process leading to scalable manufacturing of microdevices directly on silicon chips. This can be potentially achieved by using porous carbon films.

Continuous carbon coatings had been produced from silicon carbide using chlorine gas etching at high temperature [10]. Bulk TiC-CDC thin-films synthesized by the chlorination of TiC ceramics have proved to be a promising materials for supercapacitors with volumetric capacitance as high as $180 \mathrm{~F} \mathrm{~cm}^{-3}$, compared to $\sim 50 \mathrm{~F} \mathrm{~cm}^{-3}$ for conventional rolled films based on carbon powders [11]. The objective of the current study is to produce CDC electrodes using a TiC precursor already sputtered on a Si substrate. This is a promising technology compatible with MEMS type micro-devices, which has been demonstrated for supercapacitors in a sandwich configuration [12]. A volumetric capacitance as high as $180 \mathrm{~F} \mathrm{~cm}^{-3}$ was obtained in sandwich configurations, in agreement with prior results. However, MEMS systems need micro-supercapacitors in an on-chip planar interdigitated configuration without any polymer separators or binders. Moreover, they must be produced by technologies compatible with electronic device fabrication.

In this work, we report for the first time, the preparation of micro-supercapacitors based on $\mathrm{TiC}-\mathrm{CDC}$ thin films using conventional microfabrication processes. They present an alternative to micro-supercapacitors based on carbon powder and produced using various printing or electrophoresis deposition techniques, with much higher density materials, higher purity (no organic binders), and the possibility to tune the porosity with high accuracy. Optimization of this process may lead to microsupercapacitors with much higher energy density compared to prior technologies.

\section{Experimental}

Micro-supercapacitors with interdigitated configuration were fabricated using conventional micro-fabrication techniques: reactive magnetron sputtering of TiC films, photolithography and reactive ion etching (RIE) of TiC to create an interdigitated pattern, chlorination of TiC to transform the carbide into highly porous TiCCDC, which is the active material of the micro-supercapacitor, and metallic current collectors ( $\mathrm{Ti} / \mathrm{Au}$ or $\mathrm{Al}$ ) deposition through a patterned shadow mask.

\subsection{Fabrication process}

The fabrication process is shown in Fig. 1. The TiC film was fabricated on a $\mathrm{Si}$ wafer with a $500 \mathrm{~nm}$ thick $\mathrm{SiO}_{2}$ layer to ensure good insulation between the two electrodes. DC magnetron sputtering with a titanium target and acetylene $\left(\mathrm{C}_{2} \mathrm{H}_{2}\right)$ gas was used, as described in our previous work [13]. The pattern of interdigitated electrodes was applied on the photoresist film using photolithography and then transferred to the TiC film through RIE using $\mathrm{SF}_{6}$ as etching gas [14]. Afterwards, the TiC film reacted with chlorine for 5 min at $450{ }^{\circ} \mathrm{C}$ for converting to $\mathrm{CDC}$. The Raman spectra of the TiC-CDC film after chlorination (Fig. 2) were recorded using the excitation wavelength of $514.5 \mathrm{~nm}$. The two broad peaks around 1360 and $1600 \mathrm{~cm}^{-1}$, representing D- and G-peaks of graphite, respectively, confirmed the formation of disordered graphitic carbon. The spectra are typical of amorphous CDC films produced at low temperatures [15].

The Ti/Au current collectors, with thickness of $100 \mathrm{~nm} / 400 \mathrm{~nm}$ respectively, were evaporated onto the pattern through a designed shadow mask with narrower electrode fingers, to allow for electrolyte percolation during electrochemical characterization. The

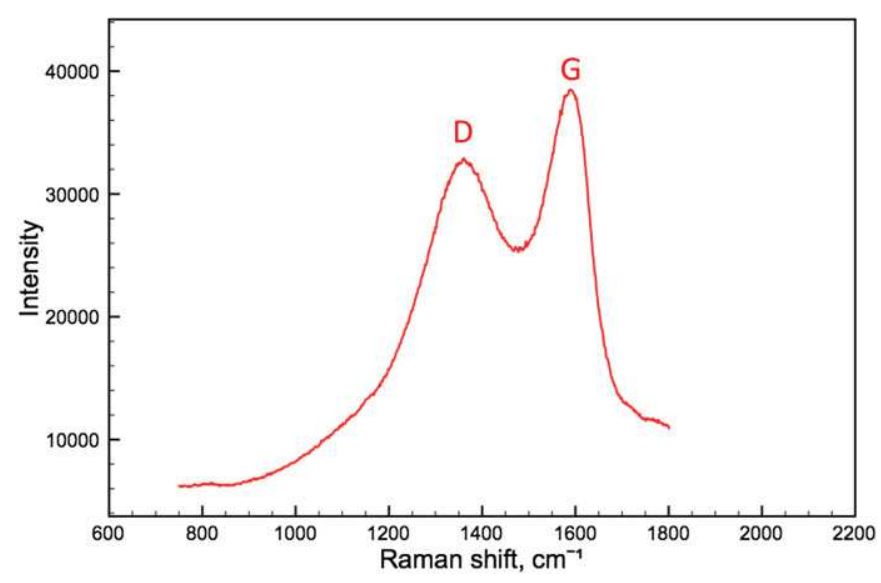

Fig. 2. Raman spectra of the TiC-CDC film chlorinated for $5 \mathrm{~min}$. 


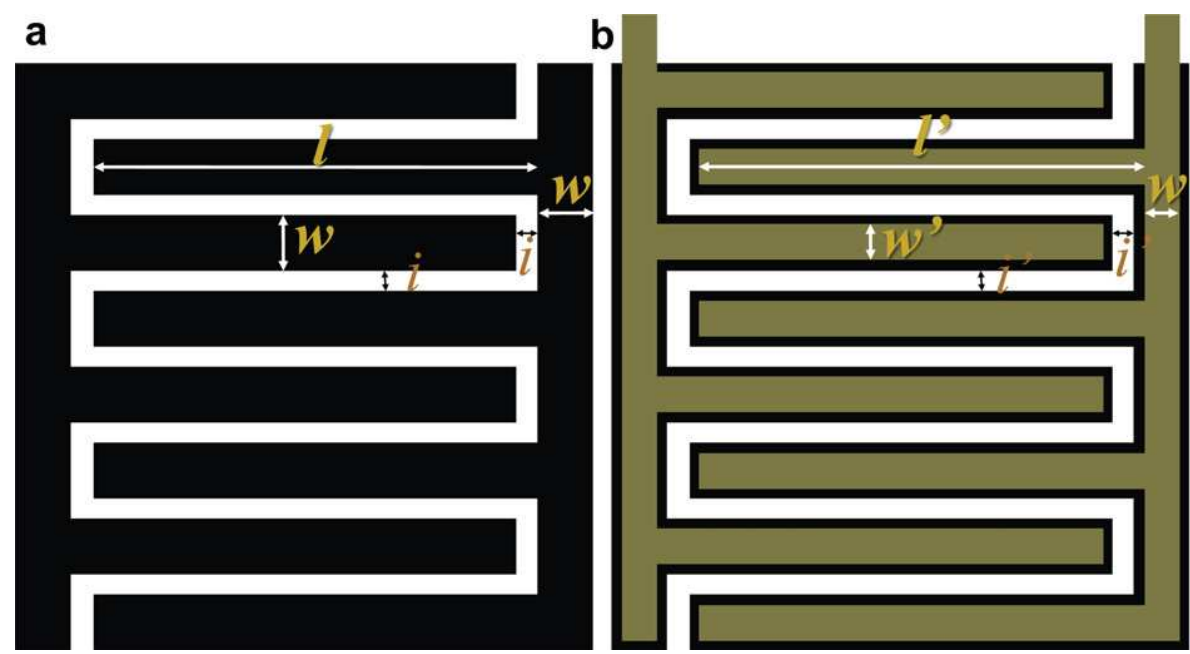

Fig. 3. a) The design of the interdigitated electrode pattern of TiC-CDC; b) The design of the hard mask used for metal current collectors.

deposited current collectors were annealed at $250{ }^{\circ} \mathrm{C}$ for $20 \mathrm{~min}$ under vacuum in order to improve the metal conductivity and release the mechanical stress between the $\mathrm{Ti} / \mathrm{Au}$ and the $\mathrm{TiC}-\mathrm{CDC}$ layers. Other samples with a different current collector (Al of $400 \mathrm{~nm}$ thickness) were implemented in similar devices using the procedures described above, except annealing.

The design of the device is a $2 \times 4$ fingers interdigitated on-chip micro-supercapacitor as shown in Fig. 3, with a finger length of $l=6.35 \mathrm{~mm}$; a finger width of $w=0.8 \mathrm{~mm}$ and an interspace distance of $i=0.15 \mathrm{~mm}$, leading thus to a footprint area of $8.1 \times 6.4 \mathrm{~mm}^{2}$. The area of a single electrode is $0.26 \mathrm{~cm}^{2} .6 .2 \mathrm{~mm}-$ long current collectors were deposited through a mask, with a width of $0.5 \mathrm{~mm}$; the current collector area on a single electrode was $0.16 \mathrm{~cm}^{2}$.

The thickness of the TiC $-\mathrm{CDC}$ film was measured to be $1.6 \mu \mathrm{m}$ by SEM, as shown in Fig. 4. The TiC-CDC layer well adhered to the $\mathrm{SiO}_{2}$ layer without any cracks or voids between the carbon film and the substrate. The CDC layer was continuous with a typical columnar texture [13], repeating that of the as-deposited TiC.

\subsection{Electrochemical testing}

The micro-supercapacitors were clipped with a connector and characterized by dipping the chip in $1 \mathrm{M}\left(\mathrm{NEt}_{4} \mathrm{BF}_{4}\right)$ in propylene

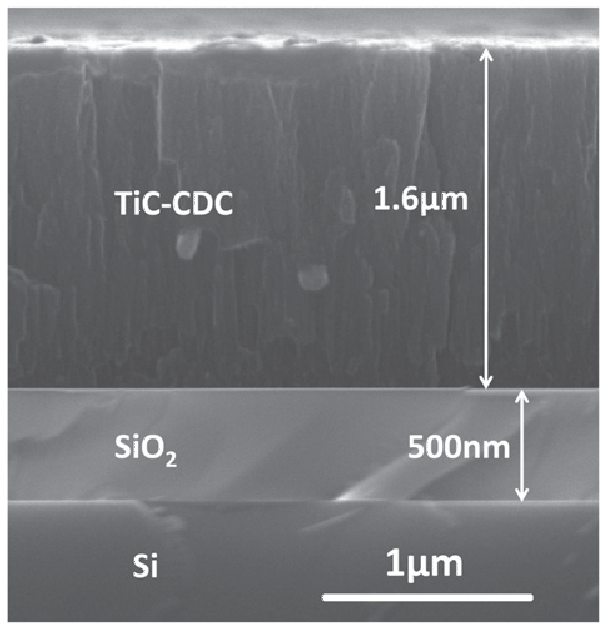

Fig. 4. The cross-section of the $\mathrm{TiC}-\mathrm{CDC}$ film based micro-supercapacitor electrode, with $1.6 \mu \mathrm{m}$ of $\mathrm{TiC}-\mathrm{CDC}$ and $500 \mathrm{~nm}$ of $\mathrm{SiO}_{2}$. carbonate (PC) electrolyte in a glove box under $\mathrm{Ar}$ atmosphere $\left(\mathrm{H}_{2} \mathrm{O}\right.$ and $\mathrm{O}_{2}$ level lower than $\left.0.1 \mathrm{ppm}\right)$. Cyclic Voltammograms (CVs) were recorded at different scan rates and Electrochemical Impedance Spectroscopy (EIS) experiments were conducted using a Biologic VMP2 potentiostat. EIS measurements were made at the rest potential by applying a sinusoidal potential signal with amplitude of $10 \mathrm{mV}$ at $\mathrm{OCV}$ and collecting the response from $50 \mathrm{kHz}$ to $10 \mathrm{mHz}$.

\section{Results and discussion}

\subsection{Electrochemical impedance spectroscopy (EIS) measurement}

Fig. 5 shows both the Nyquist plots of micro-supercapacitors with $\mathrm{Ti} / \mathrm{Au}$ current collectors (red curves) (in the web version) and that with Al current collectors (blue curves) (in the web version). The axes of the Nyquist plot are normalized to the area of one single electrode $\left(0.26 \mathrm{~cm}^{2}\right)$.

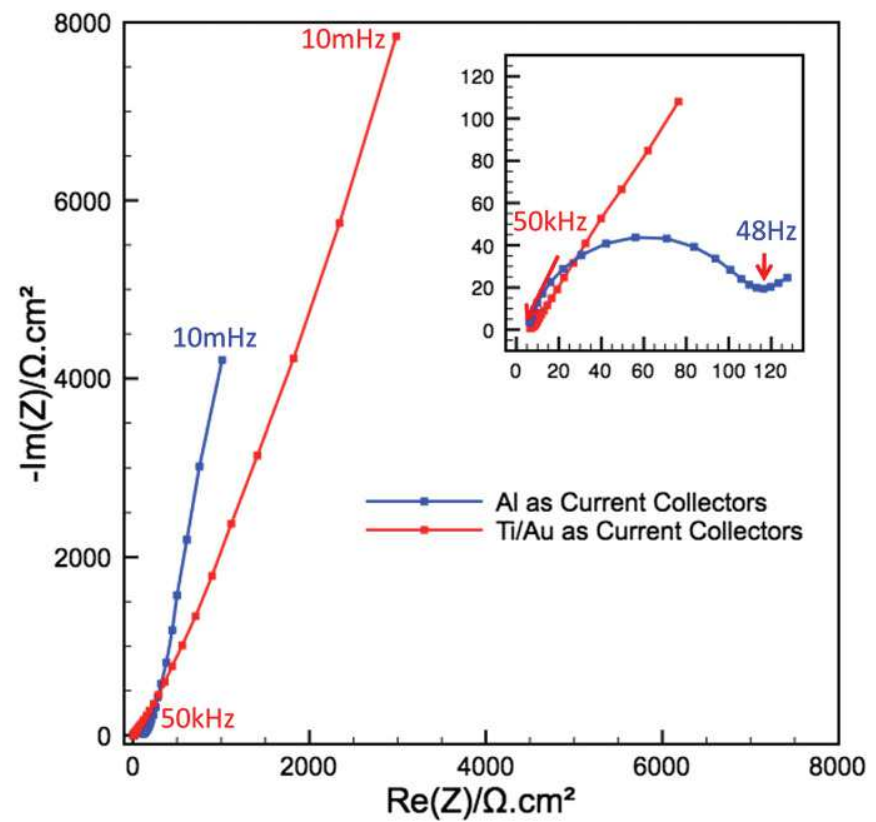

Fig. 5. Nyquist plot of the micro-supercapacitor with a) Ti/Au current collectors and b) Al current collectors in $1 \mathrm{M} \mathrm{NEt}_{4} \mathrm{BF}_{4}$ in PC. 

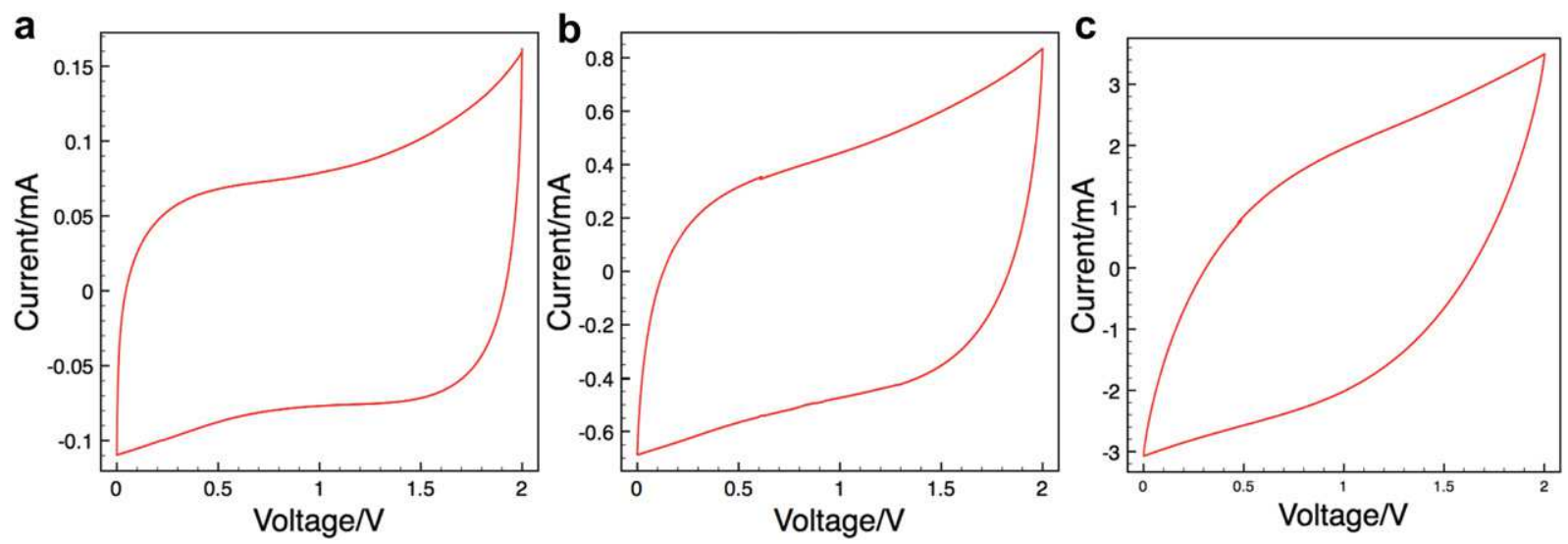

Fig. 6. CV curves of the micro-supercapacitor at scan rates of a) $100 \mathrm{mV} \mathrm{s}^{-1}$, b) $1 \mathrm{~V} \mathrm{~s}^{-1}$ and c) $10 \mathrm{~V} \mathrm{~s}^{-1}$ with Ti/Au current collectors in $1 \mathrm{M} \mathrm{NEt}_{4} \mathrm{BF}_{4}$ in $\mathrm{PC}$.

In Fig. 5, the red curve shows a constant vertical increase of the imaginary part of the impedance, which describes a capacitive behavior without redox reaction [16]. Furthermore, the lack of curvature at the intermediate frequency range signifies a good contact between the collector/carbon interface [17]. The curve shift from the theoretical $90^{\circ}$ vertical line indicates the possible presence of minor redox impurities (redox shuttle) in the electrochemical system.

Although exhibiting a constant vertical increase of the imaginary part at low frequencies, the Nyquist plot of the microdevice assembled with Al current collectors shows a loop at high frequency range that is due to the contact resistance between $\mathrm{Al}$ layer and $\mathrm{TiC}-\mathrm{CDC}$ layer, originating from slight oxidation of Al during deposition [18].

For both current collector types, the intersections between the plots and the real axis provide the Equivalent Series Resistance (ESR) of the device. These values are almost the same for the two cells, at about $6.6 \Omega \mathrm{cm}^{2}(25 \Omega)$ for the Ti/Au current collector and $6.0 \Omega \mathrm{cm}^{2}(23 \Omega)$ for the Al current collector. The absolute ESR value of the micro-supercapacitors, apparently high $(23-25 \Omega)$ is due to the small size of the device. Concerning the resistance in $\Omega \mathrm{cm}^{2}$, it is in the range of what is reported for either macro-sized supercapacitors [16] using aluminum current collectors or microsupercapacitors prepared by electrophoretic deposition [19]: around $3 \Omega \mathrm{cm}^{2}$. The difference in specific ESR for the microsupercapacitors prepared in this paper may arise from the relative high resistance of $\mathrm{CDC}$ produced below $600{ }^{\circ} \mathrm{C}[20]$.

Although both plots show a shift from the ideal vertical line at low frequencies, the larger shift observed for the systems with Au current collectors is assumed to originate from a higher catalytic activity of $\mathrm{Ti} / \mathrm{Au}$ than that of $\mathrm{Al}$, thus increasing the leakage current.

\subsection{Cyclic voltammograms}

CVs were recorded on the interdigitated on-chip micro-supercapacitor with Ti/Au current collectors in $1 \mathrm{M} \mathrm{NEt}_{4} \mathrm{BF}_{4}$ in PC electrolyte. The CV recorded at $100 \mathrm{mV} \mathrm{s}^{-1}$, shown in Fig. 6, presents a typical rectangular shape within a voltage range of $2 \mathrm{~V}$, although a shift from the ideal capacitive behavior was observed at high voltage because of the redox shuttle (impurities), which is in agreement with the EIS results described in Section 3.1. Furthermore, the micro-device could keep a relative rectangular shape, meaning little shift from ideal capacitive behavior at a scan rate of $10 \mathrm{~V} \mathrm{~s}^{-1}$, which is a very high rate even for micro-supercapacitors [19]. A capacitance of $0.74 \mathrm{mF}$ was calculated for a single on-chip device from CV data at $100 \mathrm{mV} \mathrm{s}^{-1}$ over a $2 \mathrm{~V}$ range, leading to a specific capacitance of $1.4 \mathrm{mF} \mathrm{cm}{ }^{-2}$ (per footprint area of the device). Considering the thickness of the TiC-CDC film, which is $1.6 \mu \mathrm{m}$ as shown in Fig. 4, the volumetric capacitance of the active material TiC-CDC film was calculated at $35 \mathrm{~F} \mathrm{~cm}^{-3}$. Although the capacitance is lower than that of the TiC-CDC thin-film device assembled in a sandwich configuration tested in $\mathrm{NEt}_{4} \mathrm{BF}_{4}$ acetonitrile electrolyte $\left(180 \mathrm{~F} \mathrm{~cm}^{-3}\right)$ [12], this is the first demonstration of the proof of concept of the technology. Several hypotheses can be proposed for the low capacitance achieved: the first is a much larger transport distance for ions between electrodes, as all ionic transport occurs within the plane. However, the ability of the device to operate at very high rates suggests that the capacitance is controlled by sorption and desorption of ions, rather than transport between the electrodes. In this work, $\mathrm{NEt}_{4} \mathrm{BF}_{4}$ in $\mathrm{PC}$ was used as an electrolyte whose viscosity may limit ion mobility and prevent a good impregnation of the TiC-CDC material. PC solvent leads to a larger effective ion size compared to acetonitrile based electrolytes [21] and the pores of the $450{ }^{\circ} \mathrm{C} \mathrm{TiC}-\mathrm{CDC}$ are too small for the PC-based solvent. Moreover, the leakage current from electrolysis of impurities in the system might also be a cause for the reduction

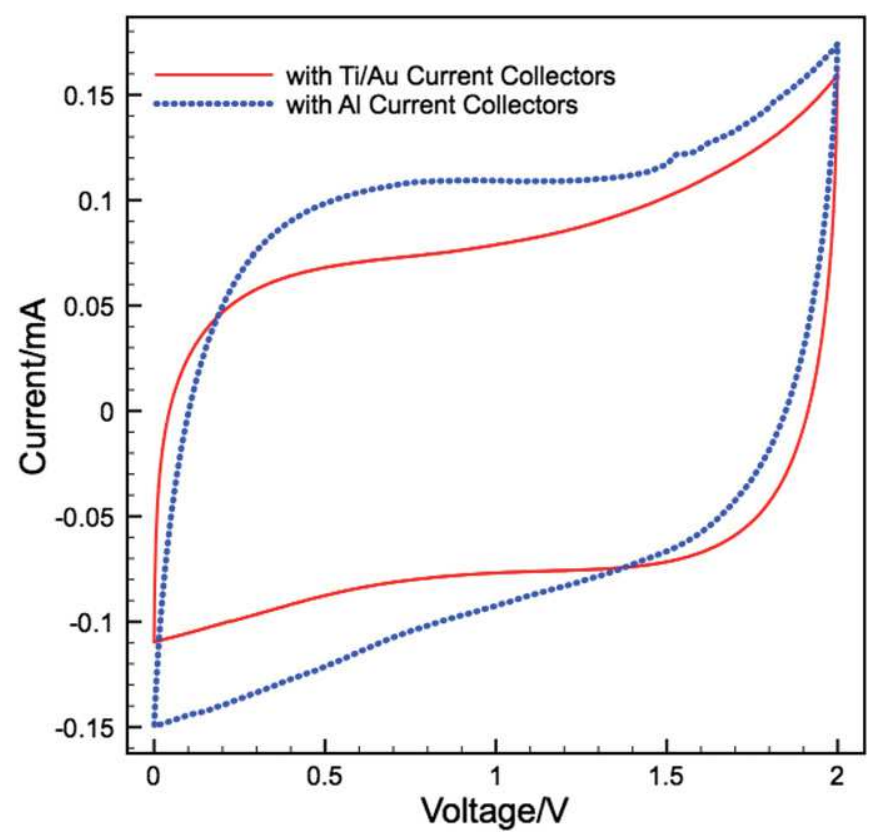

Fig. 7. $\mathrm{CV}$ curves at $100 \mathrm{mV} \mathrm{s}^{-1}$ for devices with different types of current collectors in $1 \mathrm{M} \mathrm{NEt}_{4} \mathrm{BF}_{4}$ in $\mathrm{PC}$. 
of capacitance. All these possibilities will be investigated in future experiments.

Fig. 7 shows a comparison of CVs for microdevices with $\mathrm{Al}$ and Ti/Au current collectors at $100 \mathrm{mV} \mathrm{s}^{-1}$ in the same electrolyte. The device with the Al current collector has a more distorted CV, indicating an increase in the resistance of the device as explained above. A capacitance of $0.78 \mathrm{mF}$ was calculated for the whole device from the $\mathrm{CV}$ at $100 \mathrm{mV} \mathrm{s}^{-1}$ over the $2 \mathrm{~V}$ range, with specific capacitance $1.5 \mathrm{mF} \mathrm{cm}{ }^{-2}$ normalized by the footprint area and volumetric capacitance of $37 \mathrm{~F} \mathrm{~cm}^{-3}$ for electrode material. These extracted capacitances are very close to the results obtained on the micro-supercapacitors with Ti/Au current collectors.

The prepared $\mathrm{TiC}-\mathrm{CDC}$ micro-supercapacitors showed a maximum specific energy of $3.0 \mathrm{~mJ} \mathrm{~cm}^{-2}$ and a maximum specific power of $84 \mathrm{~mW} \mathrm{~cm}{ }^{-2}$. Compared to the literature data, the energy and power performance are within the range of values reported for carbon-based micro-supercapacitors $[8,9,22]$ with the major advantage of being a simple micro-fabrication process. The specific power and energy performance may be further increased by improving the design of the cell, tuning the carbon pore size to the electrolyte ion size and by optimizing the interface between the carbon film and the current collector.

\section{Conclusion}

Micro-supercapacitors with interdigitated monolithic TiC-CDC film electrodes have been produced on a Si wafer using a conventional micro-fabrication process. The pure carbon film was produced by chlorinating TiC film sputtered onto a silicon wafer. The prepared micro-devices were characterized by electrochemical impedance spectroscopy and cyclic voltammetry, and showed good performance $\left(1.5 \mathrm{mF} \mathrm{cm}^{-2} ; 3.0 \mathrm{~mJ} \mathrm{~cm}^{-2} ; 84 \mathrm{~mW} \mathrm{~cm}^{-2}\right)$. Thus, this study has demonstrated feasibility of manufacturing micro-devices by direct fabrication on a chip. This successful realization of on-chip micro-supercapacitors based on TiC-CDC films paves the way to a full and effective integration of micro-size energy storage devices into MEMS and electronics.

\section{Acknowledgments}

We acknowledge the Partnership Universities Fund (PUF) for funding the US-French collaboration. Microfabrication was conducted in the Micro and nano technologies platform of LAASCNRS and electrochemical characterization at CIRIMAT laboratory. Research done by M.H and Y.G. was supported by the U.S. Department of Energy, Office of Basic Energy Sciences, Division of Materials Sciences and Engineering under Award \# DE-FG0207ER46473).

\section{References}

[1] F.K. Shokoohi, J.M. Tarascon, B.J. Wilkens, Appl. Phys. Lett. 59 (1991) 1260-1262.

[2] W. Wang, M. Tian, A. Abdulagatov, S.M. George, Y.-C. Lee, R. Yang, Nano Lett. 12 (2011) 655-660.

[3] M. Roberts, P. Johns, J. Owen, D. Brandell, K. Edstrom, G. El Enany, C. Guery, D. Golodnitsky, M. Lacey, C. Lecoeur, H. Mazor, E. Peled, E. Perre, M.M. Shaijumon, P. Simon, P.-L. Taberna, J. Mater. Chem. 21 (2011) 9876-9890.

[4] J.W. Long, B. Dunn, D.R. Rolison, H.S. White, Chem. Rev. 104 (2004) 44634492.

[5] P. Simon, Y. Gogotsi, Nat. Mater. 7 (2008) 845-854.

[6] H.J. In, S. Kumar, Y. Shao-Horn, G. Barbastathis, Appl. Phys. Lett. 88 (2006).

[7] C. Ho, D. Steingart, J. Salminen, W. Sin, T. Rantala, J. Evans, P. Wright, in: Power MEMS Conference, 2006, pp. 219-222.

[8] C. Shen, X. Wang, W. Zhang, F. Kang, J. Power Sources 196 (2011) 10465-10471.

[9] Y. Jiang, Q. Zhou, L. Lin, in: 22nd International Conference on MEMS, 2009, pp. 587-590.

[10] D.A. Ersoy, M.J. McNallan, Y. Gogotsi, Mater. Res. Innov. 5 (2001) 55-62.

[11] J. Chmiola, C. Largeot, P.L. Taberna, P. Simon, Y. Gogotsi, Science 328 (2010) 480-483.

[12] M. Heon, S. Lofland, J. Applegate, R. Nolte, E. Cortes, J.D. Hettinger P.L. Taberna, P. Simon, P.H. Huang, M. Brunet, Y. Gogotsi, Energy Environ. Sci. 4 (2011) 135-138.

[13] E.N. Hoffman, G. Yushin, B.G. Wendler, M.W. Barsoum, Y. Gogotsi, Mater. Chem. Phys. 112 (2008) 587-591.

14] R. Hsiao, D. Miller, S. Nguyen, A. Kellock, Appl. Surf. Sci. 148 (1999) 1-8.

[15] S. Urbonaite, L. Halldahl, G. Svensson, Carbon 46 (2008) 1942-1947.

[16] P.L. Taberna, P. Simon, J.F. Fauvarque, J. Electrochem. Soc. 150 (2003) A292-A300.

[17] P.L. Taberna, C. Portet, P. Simon, Appl. Phys. A Mater. 82 (2006) 639-646.

[18] C. Portet, P.L. Taberna, P. Simon, E. Flahaut, J. Electrochem. Soc. 153 (2006) A649-A653.

[19] D. Pech, M. Brunet, H. Durou, P.H. Huang, V. Mochalin, Y. Gogotsi, P.L. Taberna, P. Simon, Nat. Nanotechnol. 5 (2010) 651-654.

[20] P.M. Vora, P. Gopu, M. Rosario-Canales, C.R. Pérez, Y. Gogotsi, J.J. Santiago-Avilés, J.M. Kikkawa, Phys. Rev. B 84 (2011) 155114.

[21] R. Lin, P.L. Taberna, J. Chmiola, D. Guay, Y. Gogotsi, P. Simon, J. Electrochem. Soc. 156 (2009) A7-A12.

[22] F. Liu, A. Gutes, C. Carraro, J. Chu, R. Maboudian, in: Solid-state Sensors, actuators and microsystems Conference (TRANSDUCERS), 2011 16th International, 2011, pp. 1879-1882. 